\title{
Studies on the substrate specificity of a GDP-mannose pyrophosphorylase from Salmonella enterica
}

\author{
Lu Zou, Ruixiang Blake Zheng and Todd L. Lowary*
}

\section{Full Research Paper}

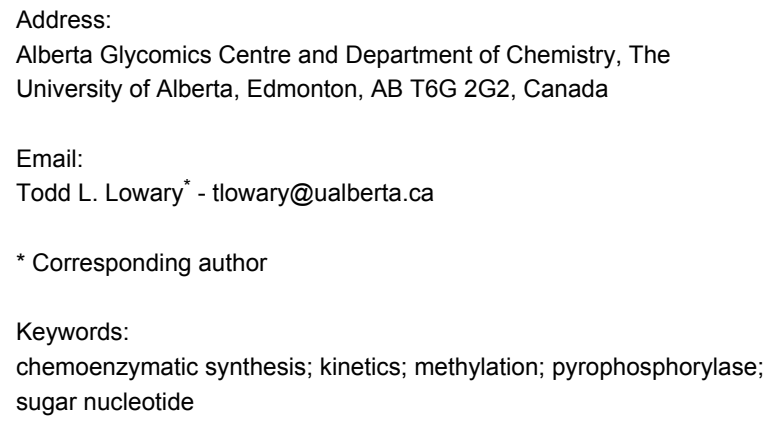

Beilstein J. Org. Chem. 2012, 8, 1219-1226. doi:10.3762/bjoc.8.136

Received: 29 May 2012

Accepted: 29 June 2012

Published: 01 August 2012

This article is part of the Thematic Series "Synthesis in the glycosciences II".

Guest Editor: T. K. Lindhorst

(C) 2012 Zou et al; licensee Beilstein-Institut. License and terms: see end of document.

\begin{abstract}
A series of methoxy and deoxy derivatives of mannopyranose-1-phosphate (Man $p$-1P) were chemically synthesized, and their ability to be converted into the corresponding guanosine diphosphate mannopyranose (GDP-Man $p$ ) analogues by a pyrophosphorylase (GDP-ManPP) from Salmonella enterica was studied. Evaluation of methoxy analogues demonstrated that GDP-ManPP is intolerant of bulky substituents at the C-2, C-3, and C-4 positions, in turn suggesting that these positions are buried inside the enzyme active site. Additionally, both the 6-methoxy and 6-deoxy Man $p$-1P derivatives are good or moderate substrates for GDP-ManPP, thus indicating that the C-6 hydroxy group of the Manp-1P substrate is not required for binding to the enzyme. When taken into consideration with other previously published work, it appears that this enzyme has potential utility for the chemoenzymatic synthesis of GDP-Man $p$ analogues, which are useful probes for studying enzymes that employ this sugar nucleotide as a substrate.
\end{abstract}

\section{Introduction}

Modified sugar nucleotide analogues are valuable probes to study glycosyltransferases and other enzymes that use these activated glycosylating agents as substrates [1-5]. The synthesis of natural and non-natural sugar nucleotides is therefore a topic of continuing interest [6]. The classical method for chemically synthesizing sugar nucleotides involves the preparation of a sugar 1-phosphate derivative followed by its coupling to an activated nucleoside monophosphate to form the key pyrophosphate moiety (Figure 1A) [7]. In general, the yield of this process is low, and the purification of the product can be tedious; hence, the development of new methods to prepare sugar nucleotides remains an area of active research [6]. 


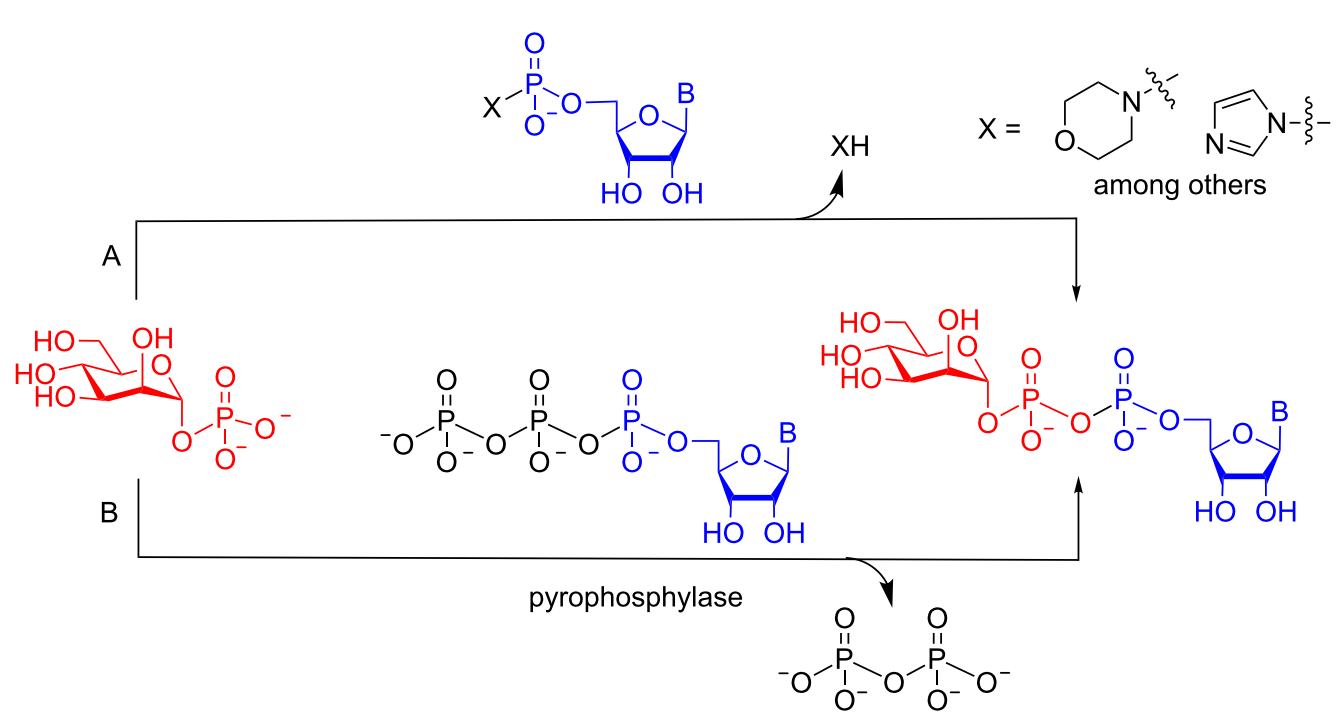

Figure 1: (A) Conventional approach for the chemical synthesis of sugar nucleotides from sugar 1-phosphates; (B) enzymatic conversion of sugar 1-phosphates into sugar nucleotides.

Although improved chemical methods have been developed [8-13], another attractive strategy is to employ a chemoenzymatic approach, in which a synthetic sugar 1-phosphate derivative is converted to the sugar nucleotide by a pyrophosphorylase (Figure 1B) [14,15]. This approach is increasingly used for the synthesis of sugar nucleotides, but a limitation is that the specificity of the pyrophosphorylase must be sufficiently broad to recognize the synthetic sugar 1-phosphate derivative. However, some of these enzymes have been demonstrated to have broad specificity, or can be engineered to have broad specificity, with regard to both the sugar 1-phosphate and nucleotide substrates [16-19].

As part of a larger study on the specificity of mannosyltransferases involved in mycobacterial glycan biosynthesis [20-22], we had the need for a panel of singly deoxygenated and methylated guanosine diphosphosphate mannopyranose (GDP-Man) derivatives. In developing a strategy for the synthesis of these compounds, we chose to take advantage of a GDP-mannose pyrophosphorylase (GDP-ManPP) from Salmonella enterica [23], which had previously been shown to have a relaxed specificity for the sugar 1-phosphate moiety [24,25]. In particular, it has been shown that the enzyme will accept mannopyranosyl 1-phosphate (Manp-1P) derivatives deoxygenated at C-2, C-3 and C-4 (1-3, Figure 2), as well as a substrate lacking the hydroxymethyl group at C-5 (4) [24]. A series monoazido derivatives (5-8) were also shown to be substrates [25]. To further probe the potential of this enzyme for the chemoenzymatic synthesis of modified GDP-Man $p$ derivatives, we describe here the preparation of all four singly methylated Man $p-1 \mathrm{P}$ analogues 9-12, as well as the 6-deoxy-Man $p-1 \mathrm{P}$ derivative 13, and an initial evaluation of their ability to serve as a substrate for S. enterica GDP-ManPP.

\section{Results and Discussion \\ Synthesis of 2-methoxy derivative 9}

The synthesis of sugar 1-phosphate 9 containing a methyl group at O-2 commenced from 3-O-benzyl-4,6-O-benzylidene- $\alpha-\mathrm{D}-$ mannopyranoside 14 [26] as illustrated in Scheme 1. Methyl-

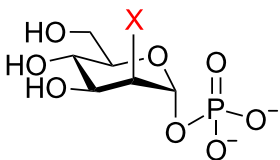

$1, \mathrm{X}=\mathrm{H}$

$5, X=N_{3}$

9, $\mathrm{X}=\mathrm{OCH}_{3}$

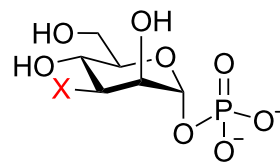

2, $\mathrm{X}=\mathrm{H}$

6, $\mathrm{X}=\mathrm{N}_{3}$

10, $\mathrm{X}=\mathrm{OCH}_{3}$

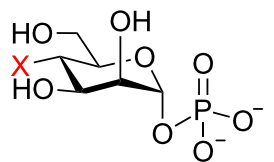

3, $\mathrm{X}=\mathrm{H}$

7, $\mathrm{X}=\mathrm{N}_{3}$

11, $\mathrm{X}=\mathrm{OCH}_{3}$

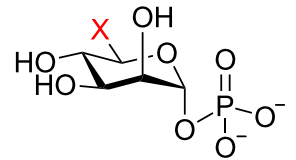

4, $\mathrm{X}=\mathrm{H}$

8, $\mathrm{X}=\mathrm{CH}_{2} \mathrm{~N}_{3}$

12, $\mathrm{X}=\mathrm{CH}_{2} \mathrm{OCH}_{3}$

13, $\mathrm{X}=\mathrm{CH}_{3}$

Figure 2: Structures of the Manp-1P derivatives (1-8) previously shown $[24,25]$ to be substrates for S. enterica GDP-ManPP and analogues 9-13 studied in this paper. 


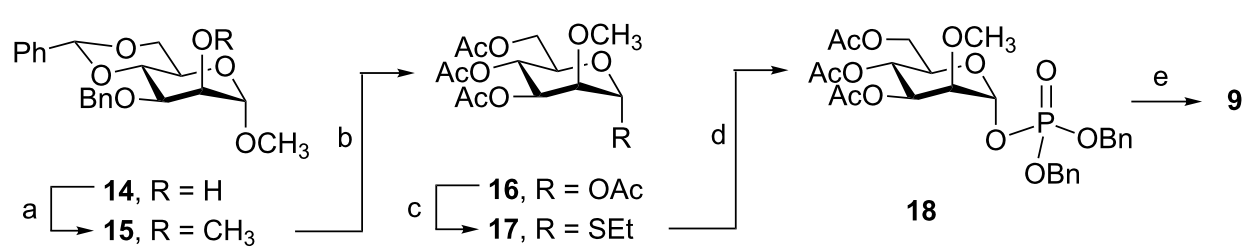

Scheme 1: Reagents and conditions: (a) $\mathrm{CH}_{3} \mathrm{l}, \mathrm{NaH}, \mathrm{DMF}, 80 \%$; (b) $\mathrm{Ac}_{2} \mathrm{O}-\mathrm{HOAc}-\mathrm{H}_{2} \mathrm{SO}_{4}, 35: 15: 1,81 \%$; (c) $\mathrm{EtSH}, \mathrm{BF}_{3} \cdot \mathrm{OEt}_{2}, \mathrm{CH}_{2} \mathrm{Cl}_{2}, 65 \%$; (d) HO-P(O) $(\mathrm{OBn})_{2}$, NIS, AgOTf, $\mathrm{CH}_{2} \mathrm{Cl}_{2}, 84 \%$; (e) (i) $\mathrm{H}_{2}, \mathrm{Pd}(\mathrm{OH})_{2}-\mathrm{C}$, toluene, $\mathrm{Et} 3 \mathrm{~N}$, pyridine; (ii) $\mathrm{CH}_{3} \mathrm{OH}-\mathrm{H}_{2} \mathrm{O}-\mathrm{Et}_{3} \mathrm{~N}, 5: 2: 1,92 \%$.

ation of the alcohol under standard conditions proceeded in $80 \%$ yield affording $\mathbf{1 5}$. The benzylidene protecting group was cleaved, together with the methyl glycoside, by acetolysis giving the tetra- $O$-acetylated compound $\mathbf{1 6}$ in $81 \%$ yield. This glycosyl acetate was converted to the corresponding thioglycoside (17), which was, in turn, coupled with dibenzyl phosphate under NIS-AgOTf activation conditions, providing compound 18 in $55 \%$ yield over two steps from $\mathbf{1 6}$. The anomeric stereochemistry in $\mathbf{1 8}$ was confirmed by the magnitude of the ${ }^{1} J_{\mathrm{C} 1, \mathrm{H} 1}$, which was $177.9 \mathrm{~Hz}$, consistent with $\alpha$-stereochemistry as described earlier by Timmons and Jakeman for rhamnopyranosyl phosphates [27]. In the other phosphorylation reactions reported in this paper, the anomeric stereochemistry was determined in an analogous manner. Compound 18 was then deprotected in two steps, namely catalytic hydrogenolysis and then, without further purification, treatment with a mixture of $\mathrm{CH}_{3} \mathrm{OH}-\mathrm{H}_{2} \mathrm{O}-\mathrm{Et}_{3} \mathrm{~N}$ 5:2:1 to remove the acetyl groups. This series of reactions gave 2-methoxy Man $p$-1P analogue 9 in $92 \%$ overall yield from 18.

\section{Synthesis of 3-methoxy derivative 10}

The preparation of the 3-methoxy Man $p$-1P analogue 10 followed a route similar to that used for the synthesis of 9 (Scheme 2). Methyl 2-O-benzyl-4,6-O-benzylidene- $\alpha$-Dmannopyranoside (19) [26] was first methylated giving 20 and then converted into glycosyl acetate 21 in $49 \%$ yield over the two steps. Subsequent thioglycosylation provided a $52 \%$ yield of 22. The protected dibenzyl phosphate $\mathbf{2 3}$ was next formed by the NIS-AgOTf promoted glycosylation of dibenzyl phosphate with 22, which afforded the desired compound, 23, in $75 \%$ yield. Hydrogenolysis of the benzyl groups and deacylation led to the formation, in $67 \%$ yield, of Manp-1P derivative $\mathbf{1 0 .}$

\section{Synthesis of 4-methoxy derivative 11}

As illustrated in Scheme 3, the synthesis of the 4-methoxy Man $p-1 \mathrm{P}$ analogue 11 started by treatment of methyl $\alpha$-Dmannopyranoside (24) with trityl chloride in pyridine. The product, 25, was then converted to the isopropylidene acetal $\mathbf{2 6}$ in $65 \%$ overall yield from $\mathbf{2 4}$. The hydroxy group in $\mathbf{2 6}$ was

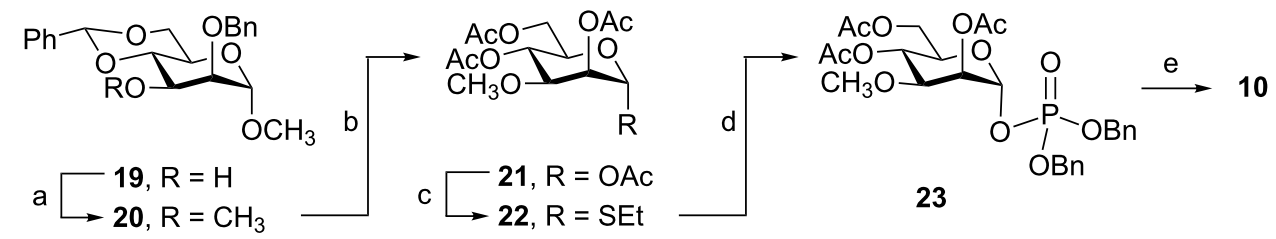

Scheme 2: Reagents and conditions: (a) $\mathrm{CH}_{3} \mathrm{l}, \mathrm{NaH}, \mathrm{DMF}, 76 \%$; (b) $\mathrm{Ac}_{2} \mathrm{O}-\mathrm{HOAc}_{-} \mathrm{H}_{2} \mathrm{SO}_{4}, 35: 15: 1,65 \%$; (c) $\mathrm{EtSH}_{1} \mathrm{BF}_{3} \cdot \mathrm{OEt}_{2}, \mathrm{CH}_{2} \mathrm{Cl}_{2}, 52 \%$; (d) $\mathrm{HO}-\mathrm{P}(\mathrm{O})(\mathrm{OBn})_{2}, \mathrm{NIS}, \mathrm{AgOTf}, \mathrm{CH}_{2} \mathrm{Cl}_{2}, 75 \%$; (e) (i) $\mathrm{H}_{2}, \mathrm{Pd}(\mathrm{OH})_{2}-\mathrm{C}$, toluene, Et ${ }_{3} \mathrm{~N}$, pyridine; (ii) $\mathrm{CH}_{3} \mathrm{OH}-\mathrm{H}_{2} \mathrm{O}-\mathrm{Et}_{3} \mathrm{~N}, 5: 2: 1,67 \%$.

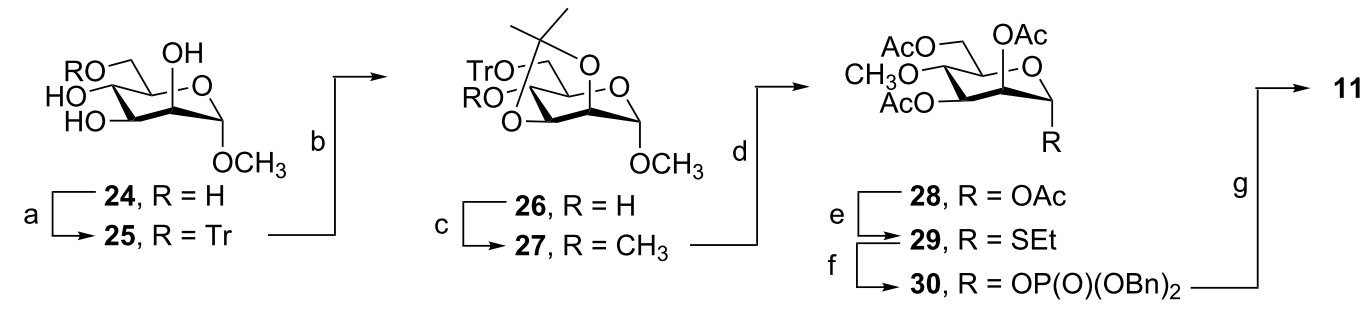

Scheme 3: Reagents and conditions: (a) TrCl, DMAP, pyridine, 85\%; (b) DMP, p-TsOH, 76\%; (c) $\mathrm{CH}_{3} \mathrm{I}, \mathrm{NaH}^{\mathrm{D}} \mathrm{DMF}, 91 \%$; (d) Ac $2 \mathrm{O}-\mathrm{HOAc}-\mathrm{H}_{2} \mathrm{SO}$, $35: 15: 1,55 \%$; (e) EtSH, $\mathrm{BF}_{3} \cdot \mathrm{OEt}_{2}, \mathrm{CH}_{2} \mathrm{Cl}_{2}, 70 \%$; (f) $\mathrm{HO}-\mathrm{P}(\mathrm{O})(\mathrm{OBn})_{2}, \mathrm{NIS}, \mathrm{AgOTf}, \mathrm{CH}_{2} \mathrm{Cl}_{2}, 80 \%$; (g) (i) $\mathrm{H}_{2}, \mathrm{Pd}(\mathrm{OH})_{2}-\mathrm{C}$, toluene, Et 3 N, pyridine; (ii) $\mathrm{CH}_{3} \mathrm{OH}-\mathrm{H}_{2} \mathrm{O}-\mathrm{Et}_{3} \mathrm{~N}, 5: 2: 1,70 \%$. 
methylated under standard conditions $\left(\mathrm{CH}_{3} \mathrm{I}, \mathrm{NaH}\right)$ to give the 4-methoxy analogue $\mathbf{2 7}$ in $91 \%$ yield. Acetolysis of $\mathbf{2 7}$ to the corresponding glycosyl acetate $\mathbf{2 8}$, followed by reaction with ethanethiol and $\mathrm{BF}_{3} \cdot \mathrm{OEt}_{2}$, yielded thioglycoside 29 , in a modest $39 \%$ yield from 27 over two steps. This compound was then converted to 11, in 56\% yield, as outlined above, by successive phosphorylation and deprotection.

\section{Synthesis of 6-methoxy derivative 12}

Two routes, differing in the choice of protecting groups, were explored to produce the 6-methoxy Man $p$-1P derivative 12 (Scheme 4 and Scheme 5). In one route, the C-2, C-3, and C-4 hydroxy groups of the mannose residues were protected with benzyl ethers and in the other they were protected with benzoyl esters. The overall yields of these two methods were $30 \%$ and $17 \%$, respectively. In the first method (Scheme 4), the initial step was the conversion, in $78 \%$ yield, of the fully acetylated thioglycoside 31 [28] into silyl ether $\mathbf{3 2}$ by treatment with sodium methoxide and then tert-butyldiphenylchlorosilane in DMF. Benzylation of $\mathbf{3 2}$ using benzyl bromide and sodium hydride gave 33 in $84 \%$ yield. The TBDPS group was then cleaved and replaced with a methyl group to give the 6-methoxy compound 35 in $72 \%$ yield over two steps. The protected dibenzyl phosphate $\mathbf{3 6}$ was formed in 70\% yield by phosphorylation as described for the synthesis of 9-11. Catalytic hydrogenolysis in the presence of $\mathrm{NaHCO}_{3}$ was used to cleave all the benzyl groups, which gave the 6-methoxy Man $p-1 \mathrm{P}$ derivative $\mathbf{1 2}$ in $91 \%$ yield.
The second route to 12 began with methyl 2,3,4-tri-O-benzoyl$\alpha$-D-mannopyranoside (37) [29] and is illustrated in Scheme 5. Methylation of the free $\mathrm{OH}$, even under mildly basic conditions (e.g., $\mathrm{Ag}_{2} \mathrm{O}-\mathrm{CaSO}_{4}$ ), led to significant amounts of acyl group migration, and the desired product was obtained in only $52 \%$ yield. Nevertheless, enough material was produced to move forward. Acetolysis conditions were used to replace the methyl group at the anomeric center in $\mathbf{3 8}$ with an acetyl group, resulting in a $96 \%$ yield of 39 . Thioglycosylation, followed by coupling of the resulting thioglycoside donor $\mathbf{4 0}$ (obtained in $75 \%$ yield) with dibenzyl phosphate, gave phosphate 41 in a yield of $67 \%$ over the two steps. The 6-methoxy Man $p-1 \mathrm{P}$ analogue 12 was obtained by catalytic hydrogenolysis of the benzyl ethers followed by treatment with $\mathrm{CH}_{3} \mathrm{OH}-\mathrm{H}_{2} \mathrm{O}-\mathrm{Et}_{3} \mathrm{~N}$ 5:2:1 providing 12 in $85 \%$ yield over two steps.

\section{Synthesis of 6-deoxy derivative 13}

The synthesis of the 6-deoxy Manp-1P analogue 13 used an intermediate (37) prepared in the course of the synthesis of the 6-methoxy analogue (Scheme 6). First, the hydroxy group of $\mathbf{3 7}$ was converted to the corresponding iodide in $65 \%$ yield, by using triphenylphospine and iodine. The product, $\mathbf{4 2}$, was then subjected to acetolysis and catalytic hydrogenation, which gave 6-deoxy glycosyl acetate derivative $\mathbf{4 3}$ in $\mathbf{7 2} \%$ yield. The subsequent thioglycosylation, phosphorylation and deprotection steps proceeded, as outlined above, to give the 6-deoxy Man $p$-1P 13 in $43 \%$ yield over four steps.

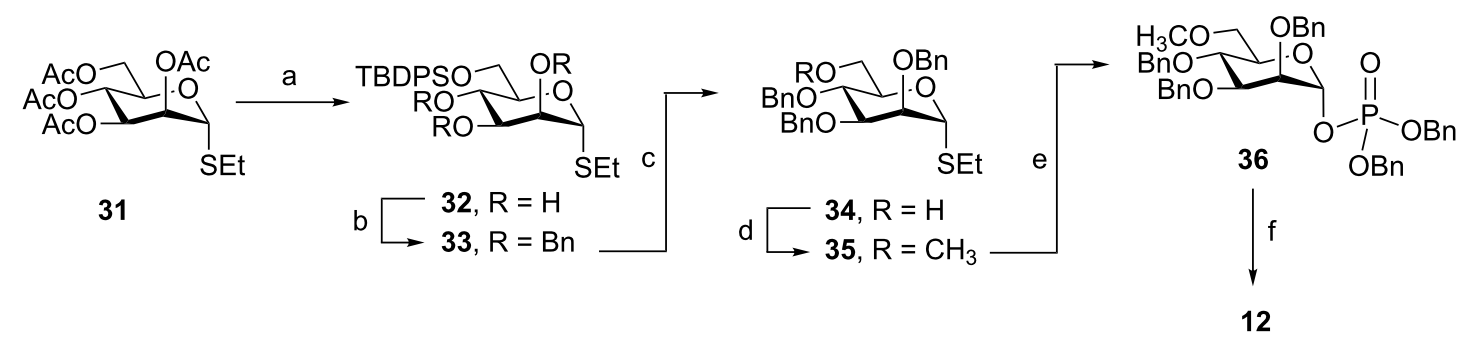

Scheme 4: Reagents and conditions: (a) (i) $\mathrm{NaOCH}_{3}, \mathrm{CH}_{3} \mathrm{OH}$; (ii) TBDPSCl, imidazole, DMF, 78\%; (b) BnBr, NaH, TBAl, 84\%; (c) TBAF, THF, 83\%; (d) $\mathrm{CH}_{3}$ l, NaH, DMF, $87 \%$; (e) $\mathrm{HO}-\mathrm{P}(\mathrm{O})(\mathrm{OBn})_{2}, \mathrm{NIS}, \mathrm{AgOTf}, \mathrm{CH}_{2} \mathrm{Cl}_{2}, 70 \%$; (f) $\mathrm{H}_{2}, \mathrm{Pd}(\mathrm{OH})_{2}-\mathrm{C}, \mathrm{NaHCO}_{3}, \mathrm{CH}_{3} \mathrm{OH}, 91 \%$.

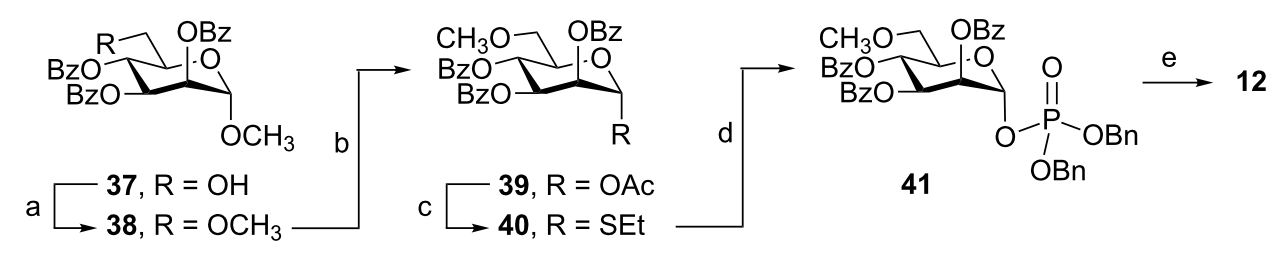

Scheme 5: Reagents and conditions: (a) $\mathrm{Ag}_{2} \mathrm{O}, \mathrm{CaSO}_{4}, \mathrm{CH}_{3} \mathrm{I}, 52 \%$; (b) $\mathrm{Ac}_{2} \mathrm{O}-\mathrm{HOAc}-\mathrm{H}_{2} \mathrm{SO}_{4}, 70: 30: 1,96 \%$; (c) $\mathrm{EtSH}, \mathrm{BF}_{3} \cdot \mathrm{OEt}_{2}, \mathrm{CH}_{2} \mathrm{Cl}_{2}, 75 \%$; (d) $\mathrm{HO}-\mathrm{P}(\mathrm{O})(\mathrm{OBn})_{2}$, NIS, AgOTf, $\mathrm{CH}_{2} \mathrm{Cl}_{2}, 89 \%$; (e) (i) $\mathrm{H}_{2}, \mathrm{Pd}(\mathrm{OH})_{2}-\mathrm{C}$, toluene, Et $3 \mathrm{~N}$, pyridine; (ii) $\mathrm{CH}_{3} \mathrm{OH}-\mathrm{H}_{2} \mathrm{O}-\mathrm{Et}_{3} \mathrm{~N}, 5: 2: 1,85 \%$. 


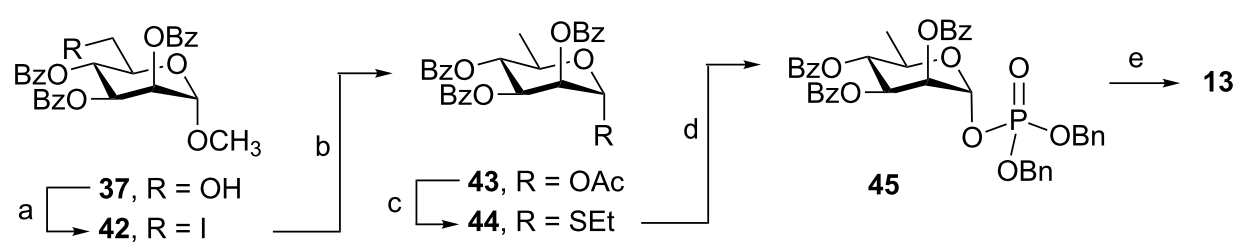

Scheme 6: Reagents and conditions: (a) $\mathrm{PPh}_{3}$, imidazole, $\mathrm{I}_{2}, 65 \%$; (b) (i) $\mathrm{Ac}_{2} \mathrm{O}-\mathrm{HOAc}-\mathrm{H}_{2} \mathrm{SO}_{4}, 35: 15: 1$; (ii) $\mathrm{Pd}-\mathrm{C}, \mathrm{H}_{2}, \mathrm{Et}_{3} \mathrm{~N}, \mathrm{EtOAc}, 72 \%$; (c) EtSH, $\mathrm{BF}_{3} \cdot \mathrm{OEt}_{2}, \mathrm{CH}_{2} \mathrm{Cl}_{2}, 89 \%, \alpha / \beta$ 4:1; (d) $\mathrm{HO}-\mathrm{P}(\mathrm{O})(\mathrm{OBn})_{2}$, NIS, AgOTf, $\mathrm{CH}_{2} \mathrm{Cl}_{2}, 67 \%$; (e) (i) $\mathrm{H}_{2}, \mathrm{Pd}(\mathrm{OH})_{2}-\mathrm{C}$, toluene, Et ${ }_{3} \mathrm{~N}$, pyridine;

(ii) $\mathrm{CH}_{3} \mathrm{OH}-\mathrm{H}_{2} \mathrm{O}-\mathrm{Et}_{3} \mathrm{~N}, 5: 2: 1,72 \%$.

\section{Evaluation of 9-13 as substrates for GDP- Man pyrophosphorylase}

With 9-13 in hand, each was evaluated as a substrate for the $S$. enterica GDP-ManPP. Before doing that, the recombinant protein was produced and the natural substrate for the enzyme, Manp-1P (46, Figure 3), was evaluated by incubation with the enzyme and GTP. The reaction was monitored by HPLC (Figure S1 in Supporting Information File 1) and stopped when the complete consumption of GTP was observed. Simultaneous with the loss of the GTP was the appearance of the signal for a new product, which was found to elute at a retention time similar to that for an authentic sample of GDP-Man $p$. The product was isolated, and analysis by high-resolution electrospray ionization mass spectrometry revealed an ion with $\mathrm{m} / \mathrm{z}=$ 604.0691, which corresponds to the $[\mathrm{M}-\mathrm{H}]^{-}$ion $(\mathrm{calcd} \mathrm{m} / \mathrm{z}=$ 604.0699) of GDP-Manp.

Having established that the enzyme GDP-ManPP was active, we carried out the same incubations for 9-13, and in all cases the corresponding GDP-Man $p$ analogue peaks could be observed (Figure S2 in Supporting Information File 1). However, in the case of $\mathbf{1 1}$ and $\mathbf{9}$, a peak corresponding to GDP, resulting from hydrolysis of the GDP-sugar, was also observed, and, in the case of 9, a much smaller amount of the GDP-Man $p$ analogue was produced. To confirm the identity of each GDPMan $p$ analogue, the product peaks were isolated and analysed by electrospray ionization mass spectrometry. For the reactions involving 9-12 a signal at $m / z \approx 618$ was observed, as would be expected for the $[\mathrm{M}-\mathrm{H}]^{-}$ion of the methylated GDP-Man derivatives (48-51, Figure 4). Similarly, for the reaction with 13, a signal at $m / z \approx 588$ was observed in the mass spectrum consistent with the 6-deoxy GDP-Man derivative $\mathbf{5 2}$.

\section{Relative activity of Manp-1P analogues with GDP-ManPP}

After it was established that all five Man $p-1 \mathrm{P}$ analogues could serve as substrates for GDP-ManPP, the relative activity with each was assessed. This was done by using an established colorimetric activity assay, which relies on the detection of the pyrophosphate (PPi, Figure 3 ) formed as a byproduct of the
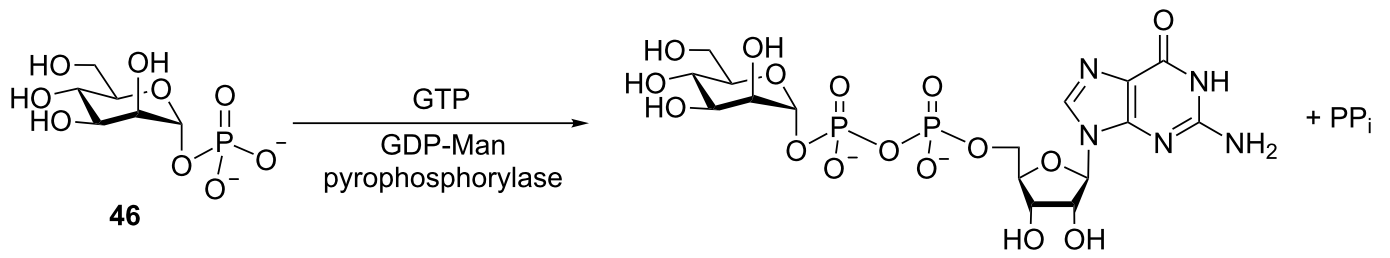

Figure 3: Reaction catalyzed by GDP-ManPP
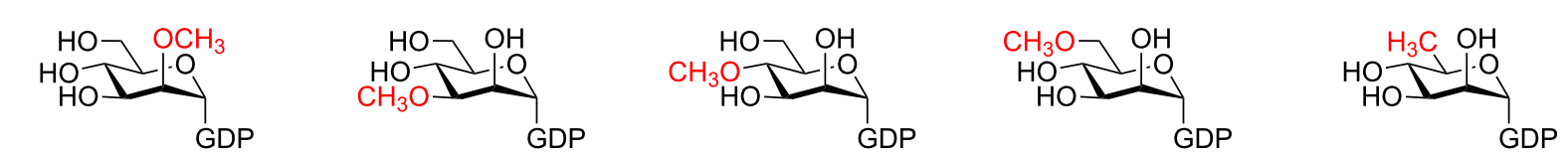

$[\mathrm{M}-\mathrm{H}]^{-} m / z=618.0848[\mathrm{M}-\mathrm{H}]^{-} m / z=618.0849[\mathrm{M}-\mathrm{H}]^{-} \mathrm{m} / \mathrm{z}=618.0848[\mathrm{M}-\mathrm{H}]^{-} \mathrm{m} / \mathrm{z}=618.0852$ calcd $\mathrm{m} / \mathrm{z}=618.0855 \quad$ calcd $\mathrm{m} / \mathrm{z}=618.0855$

48 
enzymatic reaction [30]. As illustrated in Figure 5, all five synthetic derivatives 9-13 were active as substrates, although at lower levels than the parent compound 46. The 6-methoxy (12) and 6-deoxy (13) analogues, demonstrated moderate to good relative activities, while the 2-methoxy (9), 3-methoxy (10), and 4-methoxy (11) compounds showed much lower activities. For example, the 2-methoxy, 3-methoxy, and 4-methoxy analogues displayed a 6-, 14-, and 17-fold decrease relative to 46, respectively. Because both the 6-deoxy and 6-methoxy analogues (12 and 13) showed relatively good activity it is likely that this hydroxy group does not interact significantly with the enzyme. On the other hand, because the 2-methoxy, 3-methoxy, and 4-methoxy compounds all showed a large decrease in activity, it is likely that these positions are bound tightly in the active site of the enzyme. A graphical summary of the substrate specificity for GDP-ManPP is shown in Figure 6.

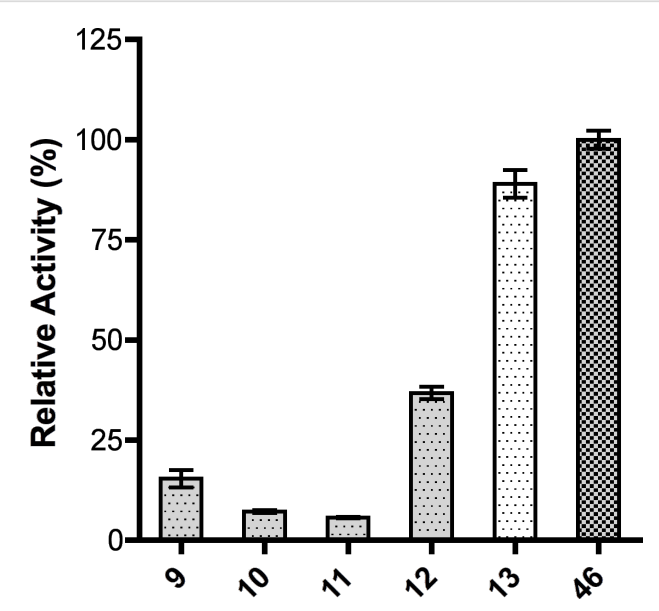

Figure 5: Comparison of the relative activity of synthetic Manp-1P analogues 9-13 for GDP-ManPP, with that of the parent compound 46. Error bars represent the standard deviation of duplicate reactions.

methoxy: poor substrate 9 deoxy: poor substrate [24] azido: moderate substrate [25]

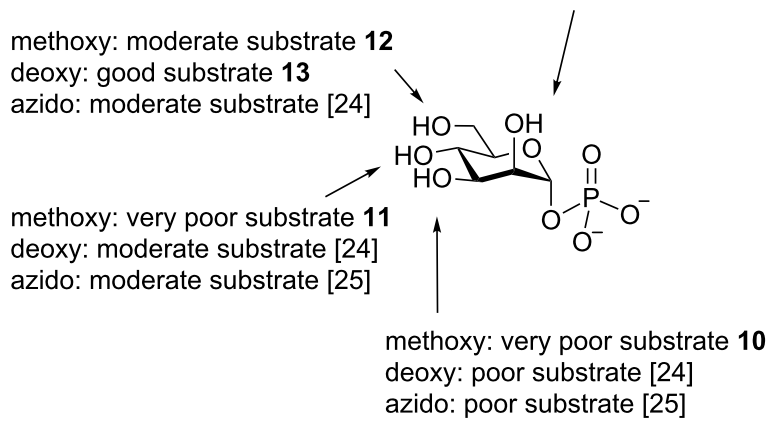

Figure 6: Summary of the substrate specificity of GDP-ManPP. Data from previous studies on the enzyme are also included as indicated [24,25].

\section{Kinetic analysis of Manp-1P analogues with GDP-ManPP}

To better understand how these 9-13 interact with GDPManPP, kinetic analyses were performed by using the colorimetric activity assay mentioned above (Table 1). Both the 6-methoxy Manp-1P (12) and 6-deoxy Manp-1P (13) derivatives bind relatively well to the enzyme, showing only a two- or three-fold increase in $K_{\mathrm{M}}$, respectively, compared to the native Man $p$-1P donor 46. The turnover rate of 6-methoxy analogue 12 is, however, much lower than the 6-deoxy counterpart (13) and the natural substrate $\mathbf{4 6}$, as substantiated by a greater than 10 -fold decrease in $k_{\text {cat }}$. Taken together, these results suggest that the C-6 hydroxy group does not engage in any critical hydrogen-bonding interactions and that a bulky substituent interferes with the rate of substrate turnover. The binding of the 2-methoxy (9) and 4-methoxy (11) analogues is very weak compared to the native substrate, as seen by the greater then 100 -fold increase in $K_{\mathrm{M}}$; consequently, the turnover rates are also low. The binding between 3-methoxy analogue $\mathbf{1 0}$ is moderate, with only a five-fold increase in the observed $K_{\mathrm{M}}$, but it shows an extremely low turnover rate. These results all suggest that GDP-ManPP is not tolerant of bulky substituents at the C-2, C-3, and C-4 positions, which is consistent with the results obtained from their relative activity. It should be noted that these trends are consistent with earlier studies of the enzyme using deoxygenated or azido analogues [24,25].

\begin{tabular}{|c|c|c|c|}
\hline compound & $K_{\mathrm{M}}(\mu \mathrm{M})$ & $\begin{array}{l}k_{\mathrm{cat}} \\
\left(\mathrm{min}^{-1}\right)\end{array}$ & $\begin{array}{l}k_{\text {cat }} / K_{\mathrm{M}} \\
\left(\min ^{-1} \cdot \mu \mathrm{M}^{-1}\right)\end{array}$ \\
\hline $\begin{array}{l}9 \text { (2-methoxy } \\
\text { analogue) }\end{array}$ & $4000 \pm 1100$ & $70 \pm 11$ & $(2 \pm 1) \times 10^{-2}$ \\
\hline $\begin{array}{l}10 \text { (3-methoxy } \\
\text { analogue) }\end{array}$ & $200 \pm 72$ & $5.2 \pm 0.7$ & $(2.6 \pm 0.1) \times 10^{-2}$ \\
\hline $\begin{array}{l}11 \text { (4-methoxy } \\
\text { analogue) }\end{array}$ & $3400 \pm 870$ & $31 \pm 4.7$ & $(9 \pm 5) \times 10^{-3}$ \\
\hline $\begin{array}{l}12 \text { (6-methoxy } \\
\text { analogue) }\end{array}$ & $120 \pm 18$ & $27 \pm 1$ & $0.23 \pm 0.06$ \\
\hline $\begin{array}{l}13 \text { (6-deoxy } \\
\text { analogue) }\end{array}$ & $70 \pm 13$ & $300 \pm 13$ & $4 \pm 1$ \\
\hline 46 (Man-1P) & $40 \pm 6$ & $360 \pm 16$ & $9 \pm 3$ \\
\hline
\end{tabular}

\section{Conclusion}

In this paper, we report the synthesis of a panel of methoxy and deoxy analogues of Man $p$-1P. Five analogues, 9-13, in which one of the hydroxy groups was methylated or deoxygenated were generated by chemical synthesis, and the ability of these compounds to be converted to the corresponding GDP-Man $p$ analogues by GDP-ManPP from S. enterica was evaluated. All the derivatives acted as substrates for GDP-ManPP, but with uniformly lower activity than the natural substrate Man-1P. The 
results suggest that the $\mathrm{C}-2, \mathrm{C}-3$, and C-4 hydroxy groups of Man $p-1 \mathrm{P}$ are bound within the active site of GDP-ManPP and the addition of a methyl group at these positions is tolerated very poorly. Conversely, the addition of a methyl group to, or deoxygenation of, O-6 had a much smaller effect, suggesting that this position protrudes from the active site, or is accommodated in a pocket that can tolerate either of these modifications. These results are consistent with earlier studies of this enzyme, which were focused on deoxygenated and azido derivatives $[24,25]$. Considered together, our studies and those published previously suggest that this enzyme can be used to access deoxy and azido derivatives of GDP-Man on a preparative scale, but that the synthesis of analogues containing more sterically demanding groups is likely to be only possible when the modifications are present on O-6.

\section{Experimental}

Detailed experimental procedures can be found in Supporting Information File 1.

\section{Supporting Information}

\section{Supporting Information File 1}

Detailed experimental procedures.

[http://www.beilstein-journals.org/bjoc/content/ supplementary/1860-5397-8-136-S1.pdf]

\section{Acknowledgements}

This work was supported by the Alberta Glycomics Centre, the University of Alberta and the Natural Sciences and Engineering Research Council of Canada. We thank Dr. Warren Wakarchuk at the National Research Council of Canada for providing the plasmid containing the GDP-ManPP gene, and Mr. Myles B. Poulin for technical assistance on the enzyme assay.

\section{References}

1. Errey, J. C.; Mann, M. C.; Fairhurst, S. A.; Hill, L.; McNeil, M. R.; Naismith, J. H.; Percy, J. M.; Whitfield, C.; Field, R. A. Org. Biomol. Chem. 2009, 7, 1009-1016. doi:10.1039/b815549f

2. Peltier, P.; Beláňová, M.; Dianišková, P.; Zhou, R.; Zheng, R. B.; Pearcey, J. A.; Joe, M.; Brennan, P. J.; Nugier-Chauvin, C.; Ferrières, V.; Lowary, T. L.; Daniellou, R.; Mikušová, K. Chem. Biol. 2010, 17, 1356-1366. doi:10.1016/j.chembiol.2010.10.014

3. Poulin, M. B.; Zhou, R.; Lowary, T. L. Org. Biomol. Chem. 2012, 10 , 4074-4087. doi:10.1039/c2ob25159k

4. Brown, C. D.; Rusek, M. S.; Kiessling, L. L. J. Am. Chem. Soc. 2012 , 134, 6552-6555. doi:10.1021/ja301723p

5. Zhang, Q.; Liu, H.-w. J. Am. Chem. Soc. 2001, 123, 6756-6766. doi:10.1021/ja010473।

6. Wagner, G. K.; Pesnot, T.; Field, R. A. Nat. Prod. Rep. 2009, 26, 1172-1194. doi:10.1039/b909621n
7. Roseman, S.; Distler, J. J.; Moffatt, J. G.; Khorana, H. G. J. Am. Chem. Soc. 1961, 83, 659-663. doi:10.1021/ja01464a035

8. Arlt, M.; Hindsgaul, O. J. Org. Chem. 1995, 60, 14-15. doi:10.1021/jo00106a007

9. Timmons, S. C.; Jakeman, D. L. Org. Lett. 2007, 9, 1227-1230. doi:10.1021/ol063068d

10. Wolf, S.; Zismann, T.; Lunau, N.; Meier, C. Chem.-Eur. J. 2009, 15, 7656-7664. doi:10.1002/chem.200900572

11. Gold, H.; van Delft, P.; Meeuwenoord, N.; Codée, J. D. C.; Filippov, D. V.; Eggink, G.; Overkleeft, H. S.; van der Marel, G. A. J. Org. Chem. 2008, 73, 9458-9460. doi:10.1021/jo802021t

12. Warnecke, S.; Meier, C. J. Org. Chem. 2009, 74, 3024-3030. doi:10.1021/jo802348h

13. Mohamady, S.; Taylor, S. D. J. Org. Chem. 2011, 76, 6344-6349. doi:10.1021/jo200540e

14. Timmons, S. C.; Hui, J. P. M.; Pearson, J. L.; Peltier, P.; Daniellou, R.; Nugier-Chauvin, C.; Soo, E. C.; Syvitski, R. T.; Ferrières, V.; Jakeman, D. L. Org. Lett. 2008, 10, 161-163. doi:10.1021/ol7023949

15. Errey, J. C.; Mukhopadhyay, B.; Kartha, K. P. R.; Field, R. A. Chem. Commun. 2004, 2706-2707. doi:10.1039/b410184g

16. Mizanur, R. M.; Pohl, N. L. B. Org. Biomol. Chem. 2009, 7, 2135-2139. doi:10.1039/b822794b

17. Barton, W. A.; Biggins, J. B.; Jiang, J.; Thorson, J. S.; Nikolov, D. B. Proc. Natl. Acad. Sci. U. S. A. 2002, 99, 13397-13402. doi:10.1073/pnas.192468299

18. Jiang, J.; Biggins, J. B.; Thorson, J. S. J. Am. Chem. Soc. 2000, 122, 6803-6804. doi:10.1021/ja001444y

19. Moretti, R.; Chang, A.; Peltier-Pain, P.; Bingman, C. A.; Phillips, G. N., Jr.; Thorson, J. S. J. Biol. Chem. 2011, 286, 13235-13243. doi:10.1074/jbc.M110.206433

20. Xia, L.; Zheng, R. B.; Lowary, T. L. ChemBioChem 2012, 13, 1139-1151. doi:10.1002/cbic.201200121

21. Tam, P.-H.; Lowary, T. L. Org. Biomol. Chem. 2010, 8, 181-192. doi:10.1039/b916580k

22. Tam, P.-H.; Besra, G. S.; Lowary, T. L. ChemBioChem 2008, 9 , 267-278. doi:10.1002/cbic.200700391

23. Elling, L.; Ritter, J. E.; Verseck, S. Glycobiology 1996, 6, 591-597. doi:10.1093/glycob/6.6.591

24. Watt, G. M.; Flitsch, S. L.; Fey, S.; Elling, L.; Kragl, U. Tetrahedron: Asymmetry 2000, 11, 621-628. doi:10.1016/S0957-4166(99)00556-X

25. Marchesan, S.; Macmillan, D. Chem. Commun. 2008, 4321-4323. doi:10.1039/b807016d

26. Tam, P.-H.; Lowary, T. L. Carbohydr. Res. 2007, 342, 1741-1772. doi:10.1016/j.carres.2007.05.001

27. Timmons, S. C.; Jakeman, D. L. Carbohydr. Res. 2008, 343, 865-874. doi:10.1016/j.carres.2008.01.046

28. Zhong, W.; Kuntz, D. A.; Ernber, B.; Singh, H.; Moremen, K. W.; Rose, D. R.; Boons, G.-J. J. Am. Chem. Soc. 2008, 130, 8975-8983. doi:10.1021/ja711248y

29. Esmurziev, A. M.; Simic, N.; Hoff, B. H.; Sundby, E. J. Carbohydr. Chem. 2010, 29, 348-367. doi:10.1080/07328303.2010.540055

30. Davis, A. J.; Perugini, M. A.; Smith, B. J.; Stewart, J. D.; Ilg, T.; Hodder, A. N.; Handman, E. J. Biol. Chem. 2004, 279, 12462-12468. doi:10.1074/jbc.M312365200 


\section{License and Terms}

This is an Open Access article under the terms of the Creative Commons Attribution License

(http://creativecommons.org/licenses/by/2.0), which permits unrestricted use, distribution, and reproduction in any medium, provided the original work is properly cited.

The license is subject to the Beilstein Journal of Organic Chemistry terms and conditions:

(http://www.beilstein-journals.org/bjoc)

The definitive version of this article is the electronic one which can be found at:

doi:10.3762/bjoc. 8.136 